\title{
Protein Phosphatase 2A as a Drug Target in the Treatment of Cancer and Alzheimer's Disease*
}

Hui WEI ${ }^{1 \dagger}$, Hui-liang ZHANG ${ }^{1 \dagger}$, Jia-zhao XIE ${ }^{1}$, Dong-li MENG ${ }^{1}$, Xiao-chuan WANG ${ }^{1}$, Dan KE ${ }^{1 \#}$, Ji ZENG ${ }^{2 \#}$, Rong LIU ${ }^{1}$ ${ }^{1}$ Department of Pathophysiology, Key Laboratory of Ministry of Education for Neurological Disorders, School of Basic Medicine, Tongji Medical College, Huazhong University of Science and Technology, Wuhan 430030, China

${ }^{2}$ Department of Clinic Laboratory, Wuhan Fourth Hospital, Tongji Medical College, Huazhong University of Science and Technology, Wuhan 430030, China

(C) The Author(s) 2020, corrected publication April 2020

\begin{abstract}
Summary: Protein phosphatase 2A (PP2A) is a major serine/threonine phosphatase which participates in the regulation of multiple cellular processes. As a confirmed tumor suppressor, PP2A activity is downregulated in tumors and its re-activation can induce apoptosis of cancer cells. In the brains of Alzheimer's disease (AD) patients, decreased PP2A activity also plays a key role in promoting tau hyperphosphorylation and $\mathrm{A} \beta$ generation. In this review, we discussed compounds aiming at modulating PP2A activity in the treatment of cancer or AD. The upstream factors that inactivate PP2A in diseases have not been fully elucidated and further studies are needed. It will help for the refinement and development of novel and clinically tractable PP2A-targeted compounds or therapies for the treatment of tumor and AD.
\end{abstract}

Key words: protein phosphatase 2A; compounds; tumor; Alzheimer's disease

\section{INTRODUCTION OF PP2A}

Phosphorylation is a common post-translational modification of proteins which participate in regulating protein functions in numerous intracellular events. Protein phosphatases (PPs) remove the phosphates from phospho-proteins. Based on the amino acids from which phosphates are removed, protein phosphatases are divided into serine/threonine or tyrosine phosphatases ${ }^{[1]}$. The serine/threonine phosphatases can be further classified into two types: type 1, namely $\mathrm{PP} 1$, and type 2 , which has three enzyme members $\mathrm{PP} 2 \mathrm{~A}, \mathrm{PP} 2 \mathrm{~B}$, and $\mathrm{PP} 2 \mathrm{C}^{[2]}$. PP2A is one of the most important serine/threonine PPs in eukaryotic organism. It is a highly conservative protein from yeast to human with its function extraordinarily complex ${ }^{[3,4]}$.

The original version of this article was revised due to a retrospective Open Access order

Hui WEI, E-mail: 510442763@qq.com; Hui-liang ZHANG, E-mail:734886938@qq.com

${ }^{\dagger}$ The authors contributed equally to this work.

\#Corresponding authors, Ji ZENG, E-mail: whzjmicro@163. com; Dan KE, E-mail: kedan@hust.edu.cn

${ }^{*}$ This study was supported by grants from National Natural Science Foundation of China (No. 31970964 and No. 31771189), Natural Science Foundation of Hubei Province, China (No. 2017CFA065) and Wuhan Health and Family Planning Commission (No. WX18C17).
As one of the most abundant enzymes, PP2A makes up for $1 \%$ of total cellular protein in some tissues ${ }^{[5]}$. It participates in many cellular functions, such as cell cycle, growth, metabolism, transformation and apoptosis $^{[6]}$. The holoenzyme of PP2A is composed of a scaffolding subunit (A), a regulatory subunit (B) and catalytic subunit $(\mathrm{C})$. Both $\mathrm{A}$ and $\mathrm{C}$ subunits have two isoforms, $\alpha$ and $\beta$. The regulatory $B$ subunit has many family members. B subunit associates with the core enzyme (formed by A and $\mathrm{C}$ subunits) to compose the heterotrimeric holoenzyme complex ${ }^{[7]}$. PP2A, together with PP1, accounts for more than $80 \%$ of the total serine/threonine phosphatases activity in mammals ${ }^{[8]}$.

PP2A is involved in the progression of cancers and is considered as a tumor suppressor ${ }^{[5]}$. The activity of PP2A is decreased in many cancers and improving PP2A activity has been tested as a promising therapeutic intervention ${ }^{[9]}$. Besides cancer, PP2A dysfunction is also involved in neurodegenerative diseases. In Alzheimer's disease (AD), PP2A inactivation leads to tau hyperphosphorylation and $\mathrm{A} \beta$ overproduction ${ }^{[5,10]}$. Therefore, compounds aiming at recovering the abnormally repressed $\mathrm{PP} 2 \mathrm{~A}$ activity may benefit both cancer and $\mathrm{AD}$ patients.

PP2Aactivity can be regulated by post-translational modification. For example, phosphorylation of threonine 304 (T304) residue or tyrosine 307 (Y307) residue can inactivate $\mathrm{PP} 2 \mathrm{~A}$, and phosphorylation at Y307 can be regarded as a marker of PP2A 
inactivation in tumors ${ }^{[1-13]}$. In addition, methylation of the carboxyl-terminal leucine 309 (L309) residue can activate $\mathrm{PP} 2 \mathrm{~A}$ through facilitating the interaction of $\mathrm{C}$ subunit with $B$ subunit ${ }^{[14,15]}$. PP2A-L309 methylation is reversible and modulated by two conserved and PP2Aspecifc enzymes, leucine carboxyl methyltransferase (LCMT1) and PP2A methylesterase (PME-1 $)^{[3,5]}$. Some compounds can modulate the above mentioned PP2A post-translational modifications, thus modulate PP2A activity.

PP2A activity is also regulated by several endogenous inhibitors such as inhibitor 1 of PP2A ( $\mathrm{I}_{1} \mathrm{PP} 2 \mathrm{~A}$ ), also known as ANP32A, inhibitor 2 of PP2A ( $\mathrm{I}_{2} \mathrm{PP} 2 \mathrm{~A}$ ), also known as SET, and cancerous inhibitor of PP2A (CIP2A $)^{[16,17]}$. Besides direct interaction with PP2A, compounds targeting these endogenous inhibitors can also modulate the activity of PP2A and may have therapeutic potential in cancer and AD.

\section{COMPOUNDS TARGETING PP2A IN THE TREATMENT OF CANCER}

\subsection{Compounds Regulating PP2A Activity Directly: Small-molecule Activators of PP2A}

Cancer is one of the greatest threats to human health, and its development and progression involves coordinate changes in both oncogene and tumor suppressor function ${ }^{[18]}$. As a tumor suppressor, PP2A is explored in many studies. It is confirmed that PP2A inhibition contributes to cancer development ${ }^{[5]}$. Tricyclic neuroleptics can regulate PP2A activity through direct binding with PP2A A $\alpha$ subunit ${ }^{[19]}$. However, application of these drugs was restricted due to CNS-related toxicity identified in clinical trials in the early $1990 \mathrm{~s}^{[19,20]}$. Recently, Sangodkar et al reported that improved small-molecule activators of PP2A (SMAPs), synthetic tricyclic sulfonamide, can inhibit the growth of KRAS-mutant lung cancers in mouse xenografts and transgenic models through binding to the PP2A A $\alpha$ scaffold subunit to drive conformational changes in PP2A. SMAPs can activate PP2A directly and lead to cell death and lung tumor suppression through inhibiting MAPK signaling pathway ${ }^{[21]}$. The application of SMAPs in the treatment of other type cancers needs further investigation.

\subsection{Compounds Regulating PP2A Activity Indirectly} 2.2.1 Compounds Targeting PP2A Inhibitor SET FTY720: As observed, SET, one of the endogenous inhibitors of PP2A, which directly binds to and modulates PP2A activity, is overexpressed in tumors ${ }^{[22]}$. PP2A activity can be recovered through relieving it from its inhibitor. A sphingolipid analogue drug, FTY720, which has been approved by FDA for the treatment of refractory multiple sclerosis, can bind to and target SET. FTY720 is identified to imitate ceramide to relieve PP2A from SET and increase PP2A activity. In experimental cancer treatment, FTY720 mediates lung cancer cell death via induction of PP2A/ RIPK1-dependent necroptosis, thus leading to tumor suppression $^{[23,24]}$.

OP449: As an oncoprotein, SET is overexpressed in many cancers such as leukemia and breast cancer $^{[25,26]}$. OP449 (formerly COG449) is a specific, physiologically stable, cell-penetrating peptide that can bind to the $\mathrm{C}$ terminal end of SET, disrupting SETPP2A interaction without changing total SET level, and resulting in PP2A activity promotion. OP449 can inhibit the growth of myeloid leukemia cells and reduce the tumor burden in mice which were xenografted with human leukemia cells. The tumor-growth repressing effect is related with decreased pS62-Myc levels and PP2A is a negative regulator of it. In breast cancer treatment, OP449 not only decreases the tumorigenic potential of breast cancer cells but also induces cancer cell apoptosis ${ }^{[26,27]}$.

\subsubsection{Compounds Targeting PP2A Inhibitor CIP2A}

Celastrol: Besides SET, another endogenous cancerous inhibitor of PP2A (CIP2A) was discovered in $2007^{[16]}$. As an oncoprotein, CIP2A is overexpressed and adversely related with the prognosis of lung and other human cancers ${ }^{[28-30]}$. Celastrol (also known as tripterine) can inhibit CIP2A, resulting in inhibition of proliferation and induction of apoptosis in nonsmall-cell lung cancer (NSCLC) ${ }^{[28]}$. Celastrol is a natural compound extracted from $T$. wilfordii or other members of the Celastraceae family ${ }^{[31]}$. It is found that celastrol could directly bind to CIP2A and promote its degradation through the ubiquitin-proteasome system. In addition, celastrol has been shown to induce cell death through mitochondrial-induced apoptotic signaling pathway but the exact mechanism still needs elucidation. Celastrol also has the potential to enhance the effects of cisplatin on lung cancer cells in vitro and in $v i v{ }^{[32-35]}$. However, whether celastrol can increase PP2A activity has not been reported and needs to be further explored.

Ethoxysanguinarine: Ethoxysanguinarine (ESG), another inhibitor of CIP2A, could downregulate CIP2A then resulting in an increase in PP2A activity ${ }^{[5,36]}$. ESG is a benzophenanthridine alkaloid extracted from plants of the Papaveraceae family. It is converted by sanguinarine upon crystallization with ammoniated ethanol during the isolation process and retains the antibacterial activity comparable of sanguinarine ${ }^{[37]}$. In the treatment of lung cancer, ESG effectively downregulates CIP2A and its downstream signaling molecules c-Myc and phospho-Akt (p-Akt), and upregulates PP2A activity. It inhibits proliferation and induces apoptosis of lung cancer cells, and also enhances the effects of cisplatin on malignant cells ${ }^{[36]}$.

Bortezomib: Bortezomib is a FDA approved anticancer drug which is used for the treatment of multiple 
myeloma, and it is also the first therapeutic proteasome inhibitor approved to be used in humans ${ }^{[38-40]}$. Bortezomib could downregulate CIP2A mRNA level but did not affect the degradation of CIP2A protein. Bortezomib treatment on triple negative breast cancer (TNBC) cells results in CIP2A inhibition with p-Akt downregulation in a dose- and time-dependent manner ${ }^{[40]}$. P-Akt is a very important player in cancer cell survival. Akt signaling activation was significantly stronger in TNBC tumor ${ }^{[41]}$. CIP2A overexpression could upregulate $\mathrm{p}$-Akt and protect breast tumor cells from apoptosis, and silencing CIP2A by siRNA can reverse the effect ${ }^{[40]}$. In addition, Bortezomib could also induce autophagy in hepatocellular carcinoma (HCC) through a CIP2A-PP2A-Akt-4EBP1 pathway ${ }^{[39]}$.

Erlotinib Derivative: Erlotinib and its derivatives are tyrosine kinase inhibitors. Erlotinib is approved by FDA for the treatment of NSCLC ${ }^{[42]}$. They can inhibit epidermal growth factor receptor (EGFR) tyrosine kinase activity through binding to the EGFR kinase domain ${ }^{[43,44]}$. In addition, Erlotinib may inhibit tumor growth through an EGFR-independent mechanism via CIP2A ${ }^{[42,45]}$. Erlotinib derivative, TD52, can induce HCC cells apoptosis through reactivation of PP2A and downregulation of CIP2A and $\mathrm{p}-\mathrm{Akt}^{[43]}$. Another derivative, TD-19, shows more potent apoptotic effects than Erlotinib in EGFR wild-type NSCLC cell lines. It can suppress CIP2A and increase PP2A activity, as well as decrease Akt phosphorylation. However, it has minimal effects on EGFR phosphorylation ${ }^{[42,46}$. The exact mechanism by which these compounds affect CIP2A and PP2A activity is indistinct. Some evidence suggests that erlotinib derivative could indirectly downregulate CIP2A transcription via disturbing the binding of a single transcription factor, Elk-1, to the CIP2A promoter ${ }^{[47]}$.

\subsubsection{Other Compounds In addition to the} compounds described above, there are compounds which can regulate PP2A activity through other pathways. For example, as a radio- and chemosensitizer, LB-100 can inhibit the PP2A-C subunit and be used together with Docetaxel for the treatment of solid tumors ${ }^{[48]}$. As a novel 2-phenyloxypyrimidine compound, TGI1002 can disrupt the interaction between SET and PP2A, then increase PP2A activity, and thus has anti-tumor effects in chronic myeloid leukemia $(\mathrm{CML})^{[49]}$. However, the precise molecular mechanisms of these compounds are elusive (fig. 1). Thus, improving the understanding of mechanisms regulating PP2A function and activity is particularly important in the development of PP2A-targeting agents ${ }^{[5,44]}$.

\section{ROLE OF PP2A IN AD}

$\mathrm{AD}$ is one of the most common neurodegenerative

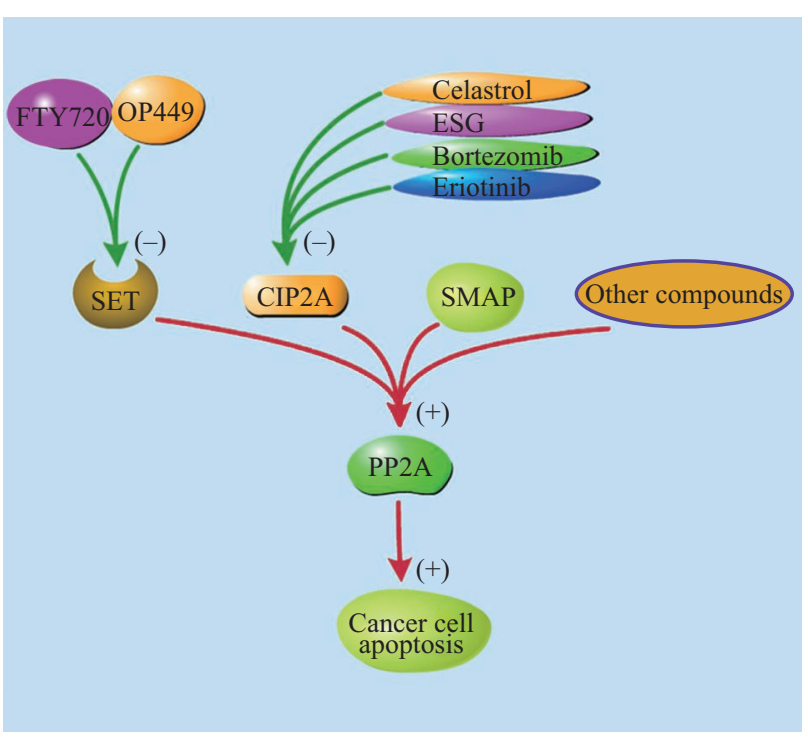

Fig. 1 Compounds targeting PP2A in the treatment of cancer

disorders, which is characterized by extracellular deposits of $\beta$-amyloid $(A \beta)$ and intracellular formation of neurofibrillary tangles (NFTs) in the brain ${ }^{[50]}$. Microtubule associated protein tau is abnormally hyperphosphorylated in AD patient brain ${ }^{[51,52]}$, which aggregates into paired helical filaments (PHF) thus forming NFTs ${ }^{[3,}{ }^{54]}$. The density of NFTs is positively related with the severity of dementia in $\mathrm{AD}$ patients ${ }^{[51]}$.

Tau is a phospho-protein and its phosphorylation is regulated by protein kinases $(\mathrm{PKs})$ and $\mathrm{PPS}^{[55]}$. Tau hyperphosphorylation is regarded as the result of tau-related PKs and PPs imbalance ${ }^{[56]}$. A lot of PKs and PPs are involved in tau hyperphosphorylation; glycogen synthase kinase-3 $\beta$ (GSK-3 $\beta$ ) and PP2A play dominant roles among them ${ }^{[57]}$. PP2A mRNA ${ }^{[58]}$, protein $^{[59]}$ and phosphatase activity are decreased in postmortem brains of AD patients. Besides PP2A, other protein phosphatases, including PP1 and PP5 are also inactivated in $\mathrm{AD}$ brains ${ }^{[60,61]}$. It is suggested that PP2A, PP1, PP5 and PP2B make up for about $71 \%, 11 \%$, $10 \%$ and $7 \%$, respectively, of the total tau phosphatase activity in human brain ${ }^{[62]}$. Therefore, decreased PP2A activity is critical to tau hyperphosphorylation and increasing PP2A activity may be an effective therapy for the treatment of $\mathrm{AD}$.

PP2A inhibition may also accelerate the formation of extracellular deposits of $A \beta$. Decreased activity of PP2A can increase amyloid precursor protein (APP) phosphorylation; improved phosphorylation at APP-Thr-668 can increase the generation of $A \beta$ and ultimately amyloid plaque formation ${ }^{[63,64]}$. At the same time, decreased PP2A methylation may induce PP2A activity inhibition and thus activate c-jun $\mathrm{N}$-terminal kinases (JNKs), leading to AD-relevant neuronal cell death ${ }^{[65]}$. JNKs control the apoptotic process and can induce cell death in several neurodegenerative 
disorders ${ }^{[66]}$. Until now, the underlying mechanism of PP2A inactivation in AD is poorly understood ${ }^{[10,67]}$.

\section{COMPOUNDS REGULATING PP2A ACTIVITY IN AD TREATMENT}

\subsection{SEW2871}

SEW2871 is a selective sphingosine-1-phosphate receptor 1 (S1PR1) agonist ${ }^{[68]}$. S1P and its receptor signaling pathways are involved in plenty of physiological and pathological processes. S1P also plays a key role in the development of neural tube and vascular system during embryogenesis ${ }^{[69]}$. As reported, SEW2871 treatment can markedly decrease p-Tau-Ser262 level without changing total tau level. This effect appears to be quite specific because it shows mild effect in regulating p-Tau-Ser396 reside and completely no influence on the modulation of p-Ser199/202 and p-Ser404 residues ${ }^{[68]}$. It has been reported that $\mathrm{p}$-Tau-Ser262 phosphorylation is affected preferentially by AMPK activation ${ }^{[70]}$. SEW2871 treatment can decrease AMPK phosphorylation at its Thr172 residue and increase PP2A activity via reducing its phosphorylation and improving its methylation ${ }^{[68]}$. Tau hyperphosphorylation at Ser262 may be an early tau pathological event in the process of $\mathrm{AD}$ and it is vital for $A \beta$-induced toxicity ${ }^{[71]}$. Therefore, SEW2871 may have potential effect in the treatment of $\mathrm{AD}$ in the early stage.

\subsection{SCR-1693}

SCR-1693 is a synthesized tacrine-dihydropyridine hybrid which shows both acetylcholinesterase inhibitor (AChEI) and calcium channel blocker (CCB) activity ${ }^{[72,73]}$. SCR-1693 treatment results in tau dephosphorylation in HEK293/tau cells, as well as reduced $\mathrm{A} \beta$ generation in $\mathrm{N} 2 \mathrm{a} / \mathrm{APP}$ cells with unaffected cell viability ${ }^{[72]}$. In the hyperhomocysteinemia (HHcy)induced AD-like rat model, SCR-1693 can improve HHcy-induced cognitive impairments, attenuate tau hyperphosphorylation at multiple $\mathrm{AD}$-associated sites and $A \beta$ overproduction. Furthermore, it can also preserve dendrite morphologies as well as spine density and increase PP2A activity with unknown mechanism. As reported, SCR-1693 can reduce the phosphorylation of PP2Ac at Tyr307 in both prefrontal cortex and hippocampus ${ }^{[73]}$. Tyr307 phosphorylation is a PP2A inhibitory modification. Thus, the effect of SCR-1693 in reducing tau hyperphosphorylation and $\mathrm{A} \beta$ overproduction may be partly mediated by activating PP2A.

\subsection{Metal Chelators}

Cations such as zinc and iron are found in the senile plaques in $\mathrm{AD}$ brains with high concentrations ${ }^{[74-76]}$. We have reported that zinc inhibits PP2A directly through binding to PP2Ac (51-270) in vitro ${ }^{[77]}$. Zinc can also induce PP2A phosphorylation at tyrosine 307
(Y307) and lead to tau hyperphosphorylation ${ }^{[78]}$. Thus, zinc chelators have the potential to re-activate PP2A through removing the inhibitory effects of zinc, in case PP2A inhibition is partially induced by zinc binding or zinc-promoted PP2A-Y307 phosphorylation. In our study, clioquinol (CQ) as an intracelluar zinc chelator can elevate PP2A activity and decrease PP2A-Y307 phosphorylation level in human tau transgenic mice ${ }^{[78]}$.

Like zinc, iron plays a crucial role in maintaining many biological functions in all living organisms ${ }^{[79]}$. It has been observed that brain iron level increases with aging in restricted regions in $\mathrm{AD}$ brain such as the parietal cortex, motor cortex, and hippocampus ${ }^{[80]}$. Several studies show that iron promotes the amyloidosis of $A \beta$ peptides as well as tau hyperphosphorylation and accumulation $^{[81,82]}$. However, the relationship between iron and PP2A had not been illuminated.

\subsection{Natural Plant Extracts}

Till now, a number of natural plant extracts have shown the ability to reduce tau hyperphosphorylation and the formation of $A \beta$ deposits. We have found that Moringa oleifera (MO), Tamarix gallica (TG), Codonopsis pilosula polysaccharide (CPPs) and Ginkgo biloba extract EGb761 can attenuate memory deficits in AD animal model ${ }^{[83-86]}$. These natural plant extracts have the ability to decrease tau phosphorylation and increase PP2A activity but the exact mechanism is unclear. The change in PP2A activity may be attributed to the altered post-translational modifications of PP2A such as phosphorylation and methylation on the catalytic subunit. However, how these compounds affect post-translational modification of PP2A has not been clarified. Besides the above mentioned, plenty of other plant extracts have been reported, such as Betaine, Liraglutide, acetyl-l-carnitine, emodin, folate and vitamin B12 (vit-B12). All these have shown potential effect on the treatment of $\mathrm{AD}$ models but the specific mechanism is not fully explored ${ }^{[87-91]}$.

\subsection{Other Compounds}

Theoretically, most compounds that modulate PP2A activity may affect tau phosphorylation and $\mathrm{A} \beta$ generation. Some compounds, such as above mentioned, can influence the activity of SET or CIP2A and have impact on the tumor cell survival. However, whether these compounds have effects on tau phosphorylation and $A \beta$ generation has not been elucidated. There are also some compounds that can influence the post-translational modifications of PP2A. For example, eicosanoyl-5-hydroxytryptamide (EHT) can inhibit protein methyl-esterase 1 (PME1) and facilitate the methylation of PP2A in cellular systems ${ }^{[22]}$. Besides, the DNA damaging agent chloroethylnitrosurea (CENU) can induce apoptosis and PP2A methylation but the exact mechanism has not been explained ${ }^{[93]}$. Although PP2A activity can be modulated through methylation modification, the 
effects of EHT and CENU on tau phosphorylation and $\mathrm{A} \beta$ generation have not been reported. In addition, there are still some other compounds that can activate PP2A but the specific mechanism is not completely understood, such as palmitic acid ${ }^{[94]}$, melatonin ${ }^{[95]}$, troglitazone ${ }^{[96]}$, progesterone ${ }^{[97]}$, dithiolethione ${ }^{[98]}$, taurolidine ${ }^{[99]}$, forskolin and related compounds ${ }^{[100,101]}$, 4-hydroxynonena ${ }^{[102,103]}$, ebelactone $\mathrm{B}^{[104]}$, epigallocatechine gallate ${ }^{[105]}$ and 1,8-naphthyridines ${ }^{[106]}$ (fig. 2). Future studies aiming at understanding the mechanisms governing PP2A activity will be crucial to help guide the development of compounds targeting PP2A.

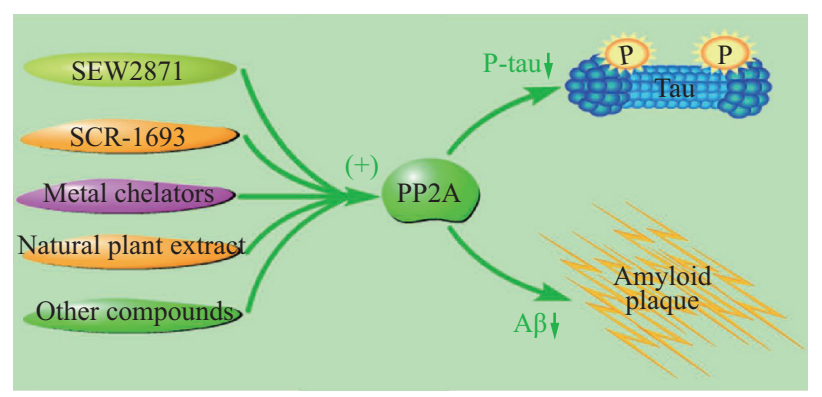

Fig. 2 Compounds regulating tau phosphorylation and $A \beta$ production through modulating PP2A activity

\section{CONCLUSION}

PP2A is a prominent phosphatase that governs the development, cell proliferation and death, cell mobility, cytoskeleton dynamics and numerous of signaling pathways. PP2A is inactivated in cancer and AD but the exact mechanism is largely unknown. Compounds which can increase PP2A activity have therapeutic effect on animal or cell models of tumor and AD. Therefore, activation of PP2A by small molecules offers a new therapeutic opportunity to treat tumor and AD. The activity of PP2A can be influenced by many factors such as mRNA transcription, post-translational modifications, inhibitory proteins and other upstream or downstream factors. Thus, there are many ways to regulate PP2A activity. Further investigation should be taken to explore the therapeutic strategies, which target PP2A, in the prevention and treatment of tumor and AD.

\section{Open Access}

This article is licensed under a Creative Commons Attribution 4.0 International License https://creativecommons.org/licenses/by/4.0/), which permits use, sharing, adaptation, distribution and reproduction in any medium or format, as long as you give appropriate credit to the original author(s) and the source, provide a link to the Creative Commons licence, and indicate if changes were made. The images or other third party material in this article are included in the article's Creative Commons licence, unless indicated otherwise in a credit line to the material. If material is not included in the article's Creative Commons licence and your intended use is not permitted by statutory regulation or exceeds the permitted use, you will need to obtain permission directly from the copyright holder. To view a copy of this licence, visit http://creativecommons.org/licenses/by/4.0/

\section{Conflict of Interest Statement}

The authors have declared that no conflict of interest exists.

\section{REFERENCES}

1 Chen MJ, Dixon JE, Manning G. Genomics and evolution of protein phosphatases. Sci Signal, 2017,10(474).pii: eaag 1796.

2 Ingebritsen TS, Cohen P. The protein phosphatases involved in cellular regulation. 1. Classification and substrate specificities. Eur J Biochem, 1983,132(2):255261

3 Shi Y. Serine/Threonine Phosphatases: Mechanism through Structure. Cell, 2009,139(3):468-484

4 Voronkov M, Braithwaite SP, Stock JB. Phosphoprotein phosphatase 2A: a novel druggable target for Alzheimer's disease. Future Med Chem, 2011,3(7):821-833

5 Sangodkar J, Farrington CC, McClinch K, et al. All roads lead to PP2A: exploiting the therapeutic potential of this phosphatase. FEBS J, 2016,283(6):1004-1024

6 Janssens V, Goris J. Protein phosphatase 2A: a highly regulated family of serine/threonine phosphatases implicated in cell growth and signalling. Biochem J, 2001,353(Pt 3):417-439

7 Cho US, Xu W. Crystal structure of a protein phosphatase 2A heterotrimeric holoenzyme. Nature, 2007,445(7123):53-57

8 Liu R, Wang JZ. Protein phosphatase 2A in Alzheimer's disease. Pathophysiology, 2009,16(4):273-277

9 Janssens V, Goris J, Van Hoof C. PP2A: the expected tumor suppressor. Curr Opin Genet Dev, 2005,15(1):3441

10 Liu R, Tian Q. Protein phosphatase 2A, a key player in Alzheimer's disease. Front Med China, 2009,3(1):8-12

11 Neviani P, Santhanam R, Trotta R, et al. The tumor suppressor PP2A is functionally inactivated in blast crisis CML through the inhibitory activity of the BCR/ABLregulated SET protein. Cancer Cell, 2005,8(5):355-368

12 Kalev P, Sablina AA. Protein phosphatase 2A as a potential target for anticancer therapy. Anticancer Agents Med Chem, 2011,11(1):38-46

13 Perrotti D, Neviani P. Protein phosphatase 2A: a target for anticancer therapy. Lancet Oncol, 2013,14(6):e229-e238

14 Longin S, Zwaenepoel K, Louis JV, et al. Selection of protein phosphatase $2 \mathrm{~A}$ regulatory subunits is mediated by the C terminus of the catalytic Subunit. J Biol Chem, 2007,282(37):26971-26980

15 Jackson JB, Pallas DC. Circumventing cellular control of PP2A by methylation promotes transformation in an Akt-dependent manner. Neoplasia, 2012,14(7):585-599

16 Junttila MR, Puustinen P, Niemela M, et al. CIP2A inhibits PP2A in human malignancies. Cell, 2007,130(1):51-62

17 Li M, Guo H, Damuni Z. Purification and characterization of two potent heat-stable protein inhibitors of protein 
phosphatase 2A from bovine kidney. Biochemistry, 1995,34(6):1988-1996

18 Zhang J, Yang PL, Gray NS. Targeting cancer with small molecule kinase inhibitors. Nat Rev Cancer, 2009,9(1): 28-39

19 Kim SH, Seo MS, Jeon WJ, et al. Haloperidol regulates the phosphorylation level of the MEK-ERKp90RSK signal pathway via protein phosphatase 2A in the rat frontal cortex. Int J Neuropsychopharmacol, 2008,11(4):509-517

20 Gutierrez A, Pan L, Groen RW, et al. Phenothiazines induce PP2A-mediated apoptosis in $\mathrm{T}$ cell acute lymphoblastic leukemia. J Clin Invest, 2014,124(2):644655

21 Sangodkar J, Perl A, Tohme R, et al. Activation of tumor suppressor protein PP2A inhibits KRAS-driven tumor growth. J Clin Invest, 2017,127(6):2081-2090

22 Li M, Makkinje A, Damuni Z. The myeloid leukemiaassociated protein SET is a potent inhibitor of protein phosphatase 2A. J Biol Chem, 1996,271(19):11 059-11 062

23 Mukhopadhyay A, Saddoughi SA, Song P, et al. Direct interaction between the inhibitor 2 and ceramide via sphingolipid-protein binding is involved in the regulation of protein phosphatase $2 \mathrm{~A}$ activity and signaling. FASEB J, 2009,23(3):751-763

24 Saddoughi SA, Gencer S, Peterson YK, et al. Sphingosine analogue drug FTY720 targets I2PP2A/ SET and mediates lung tumour suppression via activation of PP2A-RIPK1-dependent necroptosis. EMBO Mol Med, 2013,5(1):105-121

25 Christensen DJ, Chen Y, Oddo J, et al. SET oncoprotein overexpression in B-cell chronic lymphocytic leukemia and non-Hodgkin lymphoma: a predictor of aggressive disease and a new treatment target. Blood, 2011,118(15):4150-4158

26 Janghorban M, Farrell AS, Allen-Petersen BL, et al. Targeting c-MYC by antagonizing PP2A inhibitors in breast cancer. Proc Natl Acad Sci, 2014,111(25):91579162

27 Agarwal A, MacKenzie RJ, Pippa R, et al. Antagonism of SET Using OP449 Enhances the Efficacy of Tyrosine Kinase Inhibitors and Overcomes Drug Resistance in Myeloid Leukemia. Clin Cancer Res, 2014,20(8):20922103

28 Liu Z, Ma L, Wen ZS, et al. Cancerous inhibitor of PP2A is targeted by natural compound celastrol for degradation in non-small-cell lung cancer. Carcinogenesis, 2014,35(4):905-914

29 Come C, Laine A, Chanrion M, et al. CIP2A is associated with human breast cancer aggressivity. Clin Cancer Res, 2009,15(16):5092-5100

30 Khanna A, Bockelman C, Hemmes A, et al. MYCdependent regulation and prognostic role of CIP2A in gastric cancer. J Natl Cancer Inst, 2009,101(11):793805

31 Corson TW, Crews CM. Molecular understanding and modern application of traditional medicines: triumphs and trials. Cell, 2007,130(5):769-774

32 Shrivastava S, Jeengar MK, Reddy VS, et al. Anticancer effect of celastrol on human triple negative breast cancer: possible involvement of oxidative stress, mitochondrial dysfunction, apoptosis and PI3K/Akt pathways. Exp
Mol Pathol, 2015,98(3):313-327

33 Mou $\mathrm{H}$, Zheng Y, Zhao $\mathrm{P}$, et al. Celastrol induces apoptosis in non-small-cell lung cancer A549 cells through activation of mitochondria- and Fas/FasLmediated pathways. Toxicol In Vitro, 2011,25(5):10271032

34 Yu X, Zhou X, Fu C, et al. Celastrol induces apoptosis of human osteosarcoma cells via the mitochondrial apoptotic pathway. Oncol Rep, 2015,34(3):1129-1136

35 Lee JH, Won YS, Park KH, et al. Celastrol inhibits growth and induces apoptotic cell death in melanoma cells via the activation ROS-dependent mitochondrial pathway and the suppression of PI3K/AKT signaling. Apoptosis, 2012,17(12):1275-1286

36 Liu Z, Ma L, Wen Z, et al. Ethoxysanguinarine Induces Inhibitory Effects and Downregulates CIP2A in Lung Cancer Cells. ACS Med Chem Lett, 2014,5(2):113-118

37 Miao F, Yang X, Zhou L, et al. Structural modification of sanguinarine and chelerythrine and their antibacterial activity. Nat Prod Res, 2011,25(9):863-875

38 Homma T, Fujii J. An SOD1 deficiency aggravates proteasome inhibitor bortezomib-induced testicular damage in mice. Biochim Biophys Acta Gen Subj, 2019,1863(6):1108-1115

39 Yu HC, Hou DR, Liu CY, et al. Cancerous inhibitor of protein phosphatase $2 \mathrm{~A}$ mediates bortezomib-induced autophagy in hepatocellular carcinoma independent of proteasome. PLoS One, 2013,8(2):e55705

40 Tseng LM, Liu CY, Chang KC, et al. CIP2A is a target of bortezomib in human triple negative breast cancer cells. Breast Cancer Res, 2012,14(2):R68

41 Umemura S, Yoshida S, Ohta Y, et al. Increased phosphorylation of Akt in triple-negative breast cancers. Cancer Sci, 2007,98(12):1889-1892

42 Chao TT, Wang CY, Lai CC, et al. TD-19, an Erlotinib Derivative, Induces Epidermal Growth Factor Receptor Wild-Type Nonsmall-Cell Lung Cancer Apoptosis through CIP2A-Mediated Pathway. J Pharmacol Exp Ther, 2014,351(2):352-358

43 Yu H, Hung M, Chen Y, et al. Erlotinib derivative inhibits hepatocellular carcinoma by targeting CIP2A to reactivate protein phosphatase 2A. Cell Death Dis, 2014,5(7):e1359.

44 Connor CM, Perl A, Leonard D, et al. Therapeutic targeting of PP2A. Int J Biochem Cell Biol, 2018,96:182193

45 Chen K, Pao K, Su J, et al. Development of erlotinib derivatives as CIP2A-ablating agents independent of EGFR activity. Bioorg Med Chem, 2012,20(20):61446153

$46 \mathrm{Yu} \mathrm{HC}$, Chen HJ, Chang YL, et al. Inhibition of CIP2A determines erlotinib-induced apoptosis in hepatocellular carcinoma. Biochem Pharmacol, 2013,85(3):356-366

47 Liu C, Huang T, Huang C, et al. EGFR-independent Elk1/CIP2A signalling mediates apoptotic effect of an erlotinib derivative TD52 in triple-negative breast cancer cells. Eur J Cancer, 2017,72:112-123

48 Chung V, Mansfield AS, Braiteh F, et al. Safety, Tolerability, and Preliminary Activity of LB-100, an Inhibitor of Protein Phosphatase 2A, in Patients with Relapsed Solid Tumors: An Open-Label, Dose Escalation, First-in-Human, Phase I Trial. Clin Cancer 
Res, 2017,23(13):3277-3284

49 Wang S, Xie W, Wang D, et al. Discovery of a small molecule targeting SET-PP2A interaction to overcome BCR-ABLT315I mutation of chronic myeloid leukemia. Oncotarget, 2015,6(14):12128-12140

50 Glenner GG, Wong CW. Alzheimer's disease: initial report of the purification and characterization of a novel cerebrovascular amyloid protein. Biochem Biophys Res Commun, 1984,120(3):885-890

51 Grundke-Iqbal I, Iqbal K, Quinlan M, et al. Microtubuleassociated protein tau. A component of Alzheimer paired helical filaments. J Biol Chem, 1986,261(13):60846089

52 Iqbal K, Grundke-Iqbal I, Zaidi T, et al. Defective brain microtubule assembly in Alzheimer's disease. Lancet, 1986,2(8504):421-426

53 Wang J, Xia Y, Grundke-Iqbal I, et al. Abnormal Hyperphosphorylation of Tau: Sites, Regulation, and Molecular Mechanism of Neurofibrillary Degeneration. J Alzheimers Dis, 2012,33(s1):S123-S139

54 Grundke-Iqbal I, Iqbal K, Tung YC, et al. Abnormal phosphorylation of the microtubule-associated protein X (tau) in Alzheimer cytoskeletal pathology. Proc Natl Acad Sci USA, 1986,83(13):4913-4917

55 Gong CX, Shaikh S, Wang JZ, et al. Phosphatase activity toward abnormally phosphorylated tau: decrease in Alzheimer disease brain. J Neurochem, 1995,65(2):732738

56 Tanimukai H, Kudo T, Tanaka $\mathrm{T}$, et al. Novel therapeutic strategies for neurodegenerative disease. Psychogeriatrics, 2009,9(2):103-109

57 Cho JH, Johnson GV. Glycogen synthase kinase 3 beta induces caspase-cleaved tau aggregation in situ. J Biol Chem, 2004,279(52):54716-54723

58 Vogelsberg-Ragaglia V, Schuck T, Trojanowski JQ, et al. PP2A mRNA expression is quantitatively decreased in Alzheimer's disease hippocampus. Exp Neurol, 2001, 168(2):402-412

59 Sontag E, Luangpirom A, Hladik C, et al. Altered expression levels of the protein phosphatase 2A ABalphaC enzyme are associated with Alzheimer disease pathology. J Neuropathol Exp Neurol, 2004, 63 (4):287-301

60 Gong CX, Singh TJ, Grundke-Iqbal I, et al. Phosphoprotein phosphatase activities in Alzheimer disease brain. J Neurochem, 1993,61(3):921-927

61 Wang J, Tung YC, Wang Y, et al. Hyperphosphorylation and accumulation of neurofilament proteins in Alzheimer disease brain and in okadaic acid-treated SY5Y cells. FEBS Lett, 2001,507(1):81-87

62 Liu F, Grundke-Iqbal I, Iqbal K, et al. Contributions of protein phosphatases PP1, PP2A, PP2B and PP5 to the regulation of tau phosphorylation. Eur J Neurosci, 2005,22(8):1942-1950

63 Lee MS, Kao SC, Lemere CA, et al. APP processing is regulated by cytoplasmic phosphorylation. J Cell Biol, 2003,163(1):83-95

64 Colombo A, Bastone A, Ploia C, et al. JNK regulates APP cleavage and degradation in a model of Alzheimer's disease. Neurobiol Dis, 2009,33(3):518-525

65 Braithwaite SP, Schmid RS, He DN, et al. Inhibition of c-Jun kinase provides neuroprotection in a model of
Alzheimer's disease. Neurobiol Dis, 2010,39(3):311317

66 Dhanasekaran DN, Reddy EP. JNK signaling in apoptosis. Oncogene, 2008,27(48):6245-6251

67 Sontag E, Nunbhakdi-Craig V, Sontag JM, et al. Protein phosphatase 2A methyltransferase links homocysteine metabolism with tau and amyloid precursor protein regulation. J Neurosci, 2007,27(11):2751-2759

68 St-Cyr Giguère F, Attiori Essis S, Chagniel L, et al. The sphingosine-1-phosphate receptor 1 agonist SEW2871 reduces Tau-Ser262 phosphorylation in rat hippocampal slices. Brain Res, 2017,1658:51-59

69 Mizugishi K, Yamashita T, Olivera A, et al. Essential role for sphingosine kinases in neural and vascular development. Mol Cell Biol, 2005,25(24):11 113-11 121

70 Domise M, Didier S, Marinangeli C, et al. AMPactivated protein kinase modulates tau phosphorylation and tau pathology in vivo. Sci Rep, 2016,6:26758

71 Iijima K, Gatt A, Iijima-Ando K. Tau Ser262 phosphorylation is critical for Abeta42-induced tau toxicity in a transgenic Drosophila model of Alzheimer's disease. Hum Mol Genet, 2010,19(15):2947-2957

72 Wang X, Xiong Y, Yang Y, et al. A novel tacrinedihydropyridine hybrid (-) SCR1693 induces tau dephosphorylation and inhibits $\mathrm{A} \beta$ generation in cells. Eur J Pharmacol, 2015,754:134-139

73 Xia Y, Liu R, Chen R, et al. Novel Multipotent AChEICCB Attenuates Hyperhomocysteinemia-Induced Memory Deficits and Neuropathologies in Rats. J Alzheimers Dis, 2014,42(3):1029-1039

74 Miller LM, Wang Q, Telivala TP, et al. Synchrotronbased infrared and $\mathrm{X}$-ray imaging shows focalized accumulation of $\mathrm{Cu}$ and $\mathrm{Zn}$ co-localized with betaamyloid deposits in Alzheimer's disease. J Struct Biol, 2006,155(1):30-37

75 Suh SW, Jensen KB, Jensen MS, et al. Histochemicallyreactive zinc in amyloid plaques, angiopathy, and degenerating neurons of Alzheimer's disease brains. Brain Res, 2000,852(2):274-278

76 Mezzaroba L, Alfieri DF, Colado SA, et al. The role of zinc, copper, manganese and iron in neurodegenerative diseases. Neurotoxicology, 2019,74:230-241

77 Xiong Y, Luo D, Wang X, et al. Zinc binds to and directly inhibits protein phosphatase $2 \mathrm{~A}$ in vitro. Neurosci Bull, 2015,31(3):331-337

78 Xiong Y, Jing XP, Zhou XW, et al. Zinc induces protein phosphatase $2 \mathrm{~A}$ inactivation and tau hyperphosphorylation through Src dependent PP2A (tyrosine 307) phosphorylation. Neurobiol Aging, 2013, 34(3):745-756

79 Beard JL. Iron biology in immune function, muscle metabolism and neuronal functioning. J Nutr, 2001,131(2S-2):568S-579S, 580S

80 Tao Y, Wang Y, Rogers JT, et al. Perturbed iron distribution in Alzheimer's disease serum, cerebrospinal fluid, and selected brain regions: a systematic review and meta-analysis. J Alzheimers Dis, 2014,42(2):679690

81 Amit T, Avramovich-Tirosh Y, Youdim MB, et al. Targeting multiple Alzheimer's disease etiologies with multimodal neuroprotective and neurorestorative iron chelators. FASEB J, 2008,22(5):1296-1305 
82 Liu B, Moloney A, Meehan S, et al. Iron promotes the toxicity of amyloid beta peptide by impeding its ordered aggregation. J Biol Chem, 2011,286(6):4248-4256

83 Salissou M, Mahaman Y, Zhu F, et al. Methanolic extract of Tamarix Gallica attenuates hyperhomocysteinemia induced AD-like pathology and cognitive impairments in rats. Aging (Albany NY), 2018,10(11):3229-3248

84 Zhang Q, Xia Y, Luo H, et al. Codonopsis pilosula Polysaccharide Attenuates Tau Hyperphosphorylation and Cognitive Impairments in hTau Infected Mice. Front Mol Neurosci, 2018,11:437

85 Zeng K, Li M, Hu J, et al. Ginkgo biloba Extract EGb761 Attenuates Hyperhomocysteinemia-induced AD Like Tau Hyperphosphorylation and Cognitive Impairment in Rats. Curr Alzheimer Res, 2018,15(1):89-99

86 Mahaman Y, Huang F, Wu M, et al. Moringa Oleifera Alleviates Homocysteine-Induced Alzheimer's DiseaseLike Pathology and Cognitive Impairments. J Alzheimers Dis, 2018,63(3):1141-1159

87 Chai GS, Jiang X, Ni ZF, et al. Betaine attenuates Alzheimer-like pathological changes and memory deficits induced by homocysteine. J Neurochem, 2013, 124(3):388-396

88 Zhang Y, Xie JZ, Xu XY, et al. Liraglutide Ameliorates Hyperhomocysteinemia-Induced Alzheimer-Like Pathology and Memory Deficits in Rats via Multi-molecular Targeting. Neurosci Bull, 2019,35(4):724-734

89 Zhou P, Chen Z, Zhao N, et al. Acetyl-L-carnitine attenuates homocysteine-induced Alzheimer-like histopathological and behavioral abnormalities. Rejuvenation Res, 2011,14(6):669-679

90 Zeng P, Shi Y, Wang XM, et al. Emodin Rescued Hyperhomocysteinemia-Induced Dementia and Alzheimer's Disease-Like Features in Rats. Int J Neuropsychopharmacol, 2019,22(1):57-70

91 Wei W, Liu YH, Zhang CE, et al. Folate/vitamin-B12 prevents chronic hyperhomocysteinemia-induced tau hyperphosphorylation and memory deficits in aged rats. J Alzheimers Dis, 2011,27(3):639-650

92 Lee KW, Chen W, Junn E, et al. Enhanced phosphatase activity attenuates alpha-synucleinopathy in a mouse model. J Neurosci, 2011,31(19):6963-6971

93 Guenin S, Schwartz L, Morvan D, et al. PP2A activity is controlled by methylation and regulates oncoprotein expression in melanoma cells: a mechanism which participates in growth inhibition induced by chloroethylnitrosourea treatment. Int $\mathrm{J}$ Oncol, 2008,32(1):49-57

$94 \mathrm{Wu} \mathrm{Y}$, Song $\mathrm{P}, \mathrm{Xu} \mathrm{J}$, et al. Activation of protein phosphatase $2 \mathrm{~A}$ by palmitate inhibits AMP-activated protein kinase. J Biol Chem, 2007,282(13):9777-9788
95 Yang X, Yang Y, Fu Z, et al. Melatonin ameliorates Alzheimer-like pathological changes and spatial memory retention impairment induced by calyculin A. J Psychopharmacol, 2011,25(8):1118-1125

96 Cho DH, Choi YJ, Jo SA, et al. Troglitazone acutely inhibits protein synthesis in endothelial cells via a novel mechanismin volving protein phosphatase 2A-dependent p70 S6 kinase inhibition. Am J Physiol Cell Physiol, 2006,291(2):C317-326

97 Liu B, Arbogast LA. Progesterone decreases tyrosine hydroxylase phosphorylation state and increases protein phosphatase $2 \mathrm{~A}$ activity in the stalk-median eminence on proestrous afternoon. J Endocrinol, 2010,204(2):209219

98 Switzer CH, Ridnour LA, Cheng RY, et al. Dithiolethione compounds inhibit Akt signaling in human breast and lung cancer cells by increasing PP2A activity. Oncogene, 2009,28(43):3837-3846

99 Aceto N, Bertino P, Barbone D, et al. Taurolidine and oxidative stress: a rationale for local treatment of mesothelioma. Eur Respir J, 2009,34(6):1399-1407

100 Neviani P, Santhanam R, Trotta R, et al. The tumor suppressor PP2A is functionally inactivated in blast crisis CML through the inhibitory activity of the BCR/ABLregulated SET protein. Cancer Cell, 2005,8(5):355-368

101 Perrotti D, Neviani P. Protein phosphatase 2A (PP2A), a drugable tumor suppressor in $\mathrm{Ph} 1(+)$ leukemias. Cancer Metastasis Rev, 2008,27(2):159-168

102 Nakashima I, Liu W, Akhand AA, et al. 4-hydroxynonenal triggers multistep signal transduction cascades for suppression of cellular functions. Mol Aspects Med, 2003,24(4-5):231-238

103 Liu W, Akhand AA, Takeda K, et al. Protein phosphatase 2A-linked and -unlinked caspase-dependent pathways for downregulation of Akt kinase triggered by 4-hydroxynonenal. Cell Death Differ, 2003,10(7):772781

104 Kowluru A, Seavey SE, Rabaglia ME, et al. Carboxylmethylation of the catalytic subunit of protein phosphatase $2 \mathrm{~A}$ in insulin-secreting cells: evidence for functional consequences on enzyme activity and insulin secretion. Endocrinology, 1996,137(6):2315-2323

105 Kitano K, Nam KY, Kimura S, et al. Sealing effects of (-)-epigallocatechin gallate on protein kinase $\mathrm{C}$ and protein phosphatase 2A. Biophys Chem, 1997,65(23):157-164

106 de Los Ríos C, Egea J, Marco-Contelles J, et al, Synthesis, inhibitory activity of cholinesterases, and neuroprotective profile of novel 1,8-naphthyridine derivatives. J Med Chem, 2010,53(14):5129-5143

(Received July 8, 2019; revised Dec. 10, 2019) 